\title{
Prevelance of Burkitt Lymphoma in Southern Tertiary Hospital of Nigeria from Jan.2007-Dec. 2012.
}

\author{
Martin Nnoli ${ }^{1}$, Nwabuko Collins .O. ${ }^{2}$, Chinenye Nnoli ${ }^{2}$
}

\begin{abstract}
:
Aim/Objectives: This is to determine the frequency of burkitt's lymphoma occurrence and most gender involved, agelyear of predilection.

Materials and Method: A sectional study of this malignant lesion was determined by extracting all the histopathological reported cases seen over a period of six years spanning from January 2007 -December 2012. The data obtained was analysed using SPSS version 16 presenting each year per sex,age/frequency of occurrences seen.

Results: It showed a relatively low frequency of occurrence in our centre possible due to the ignorance of such parents care giver, parent or late reporting after trial with alternative medicine provider/religious institutes and above all issue of low socio-economic status of most if not all patients seen within the period.

Conclusion/Recommendation: A more aggressive chemotherapeutic approach is paramount; health education and institution of cancer free treatment centres which will be a great ameliorating factor to all these patients seeking non- orthodox approach of treatment/willingness to avail themselves.
\end{abstract}

Keywords: Burkitts lymphoma, age, sex, Frequency, histology

\section{Introduction}

Burkitt lymphoma is a cancer of lymphatic system especially B-lymphocytes. It is named after the founder Dennis Parsons Burkitt, a surgeon who discovered and described the disease in 1956 while working at equatorial Africa. ${ }^{1,2}$

BurkittLymphoma(BL) is an aggressive form of NHL involving B cells. It occurs as a result of chromosome translocation involving the mycgene. This translocation disrupts of myc expression leads to abnormal cell growth and proliferation. The normal germinal centre B cell is the presumed cell of orign for BL hence gene expression analysis suggests these malignancies may use different oncogenic pathways. The rate of cell division of $\mathrm{BL}$ is one of the highest among human tumours. It is later found to be linked with epsteinbarr virus(EBV) as is the first true virus associated with the formation of cancer. ${ }^{3}$ There have been a lot of classification and WHO recently updated and defined it as B-cell lymphoma with an extremely short doubling time often seen as extranodial sites or acute leukaemia. ${ }^{4}$ There are about three clinical variants of BL recognised but all are based on deregulation of this c-myc gene by one of three chromosomal translocation. ${ }^{5}$ The gene is present at $8 \mathrm{q} 24$ often seen are $\mathrm{t}(8: 14) \mathrm{q} 24 ; \mathrm{q} 32)$, as this is about $85 \%{ }^{5}$ of all cases seen. In this case it occurs at cmyc as IGH. ${ }^{6}$ There is a variant of three way translocation $\left\{\mathrm{t}(8,14 ; 18\}\right.$ also discovered. ${ }^{7}$

Among the variants, Dennis Burkitt first noted the endemic variants which occurs at where he was working at equatorial Africa. He applaud it as a common malignancy of children in the area as these children often had chronic malaria which is believed to have resistance to EBV. This disease progresses as from the jaw or other facial bone,distal ileum,caecum,ovaries,kidney or the breast.

Other forms termed sporadic type is a NHL pattern seen outside Africa;rarely involving EBV. ${ }^{8}$ Thetumor cells appear similar to cancer cells of classical or endemic burkitt lymphoma. It is seen at ileocaecal region; involving jaw when compared to endemic variant.

The immunodeficiency associated involved the HIV infected patient; and at times seen in posttransplant with immunosuppressive drugs. ${ }^{9}$ The sporadic BL is often world wide- Asian countries and other areas. ${ }^{10,11}$ This is seen in children and adolescents with histological BL characterised by diffuse infiltration of monomorphic medium -sized neoplastic cells having basophilic cytoplasm in a background of severe mitotic figures. Often times atypical BL or burkitt like lymphoma could be seen. ${ }^{12}$

It is imperative to note that BL could appear at other sites as have been seen in an isolation at rapidly enlarging chest wall mass from skin or soft tissue in an adult as this gives a features of soft and skin tissue lymphomas including BL. ${ }^{12}$ It predominantly affects the jaw and abnormal organs (Burkitt 1958). However, BL is seen in adults but is commonly a disease of children at ages of 4 years and 8 years (Wright 1997).

Despite, the extranodal, soft and skeletal tissue appearance of the disease, it becomes pertinent for effective treatment for the staging of the disease. This is to enable effective treatment. This refinements in staging/response in treatment of children with BL have brought a lot of improvement in treatment seen over the 
years. ${ }^{13}$ The earliest staging system of Ziegler and Magreth of 1974 is still been used but that of Murphy in 1980 which was used in children with NHL. This refinement includes extra-nodal sites as skin and bone has included recent technologies \{functional imaging (Positron emission tomography (PET)\} and minimal residual disease (MRD) technology as this need to be considered. Recently MRD flow cytometry and Polymerase chain reaction (PCR) for immunologlobulin gene rearrangements has been studied and introduced into the current protocols of further investigation. Also of recent, monophentypically plays a role since this is tumors of matured B cells that expresses surface IgM, CD19, CD20,CD10, and BCL6 which is a phenotype consistent with germinal centre of B-cell origin.

Morphologically, the tumor exhibits a high mitotic index with numerous apoptotic cells, as nuclear remnants are phagocytosed by interspersed benign macrophages. These phagocytes have abundant clear cytoplasm giving a characteristics "Starry sky" appearance. If bone marrow is involved as isextranodal sitesaspirates are taken for evaluation of tumor cells.

\section{Materials And Method}

A cross-sectional study of this lesion (burkitt lymphoma) that are histologically diagnosed was extracted from the report register of the department of pathology from January 2007-december2012. The data obtained were analysed using SPSS version 16 and all were presented in data and pie-chart.

\section{RESULTS:}

2007

\begin{tabular}{|c|c|c|c|c|c|}
\hline & & Frequency & Percent & Valid Percent & Cumulative Percent \\
\hline \multirow[t]{3}{*}{ Valid } & Under 10 years & 1 & 50.0 & 50.0 & 50.0 \\
\hline & $10-20$ years & 1 & 50.0 & 50.0 & 100.0 \\
\hline & Total & 2 & 100.0 & 100.0 & \\
\hline
\end{tabular}

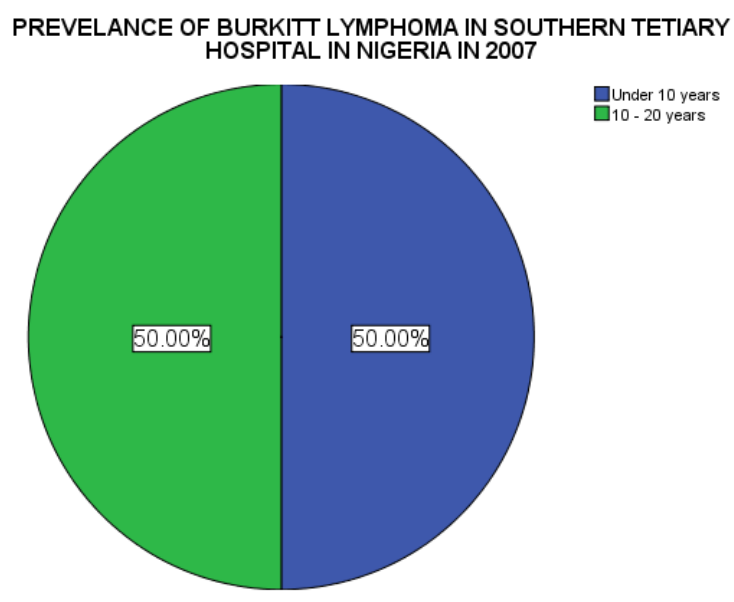

Gender
\begin{tabular}{|ll|l|l|l|l|}
\hline \multicolumn{1}{|c|}{} & Frequency & Percent & Valid Percent & Cumulative Percent \\
\hline Valid & Male & 1 & 50.0 & 50.0 & 50.0 \\
& Female & 1 & 50.0 & 50.0 & 100.0 \\
& Total & 2 & 100.0 & 100.0 & \\
\hline
\end{tabular}

2008

Age in years
\begin{tabular}{|l|l|l|l|l|}
\hline & Frequency & Percent & Valid Percent & Cumulative Percent \\
\hline Valid Under 10 years & 2 & 100.0 & 100.0 & 100.0 \\
\hline
\end{tabular}




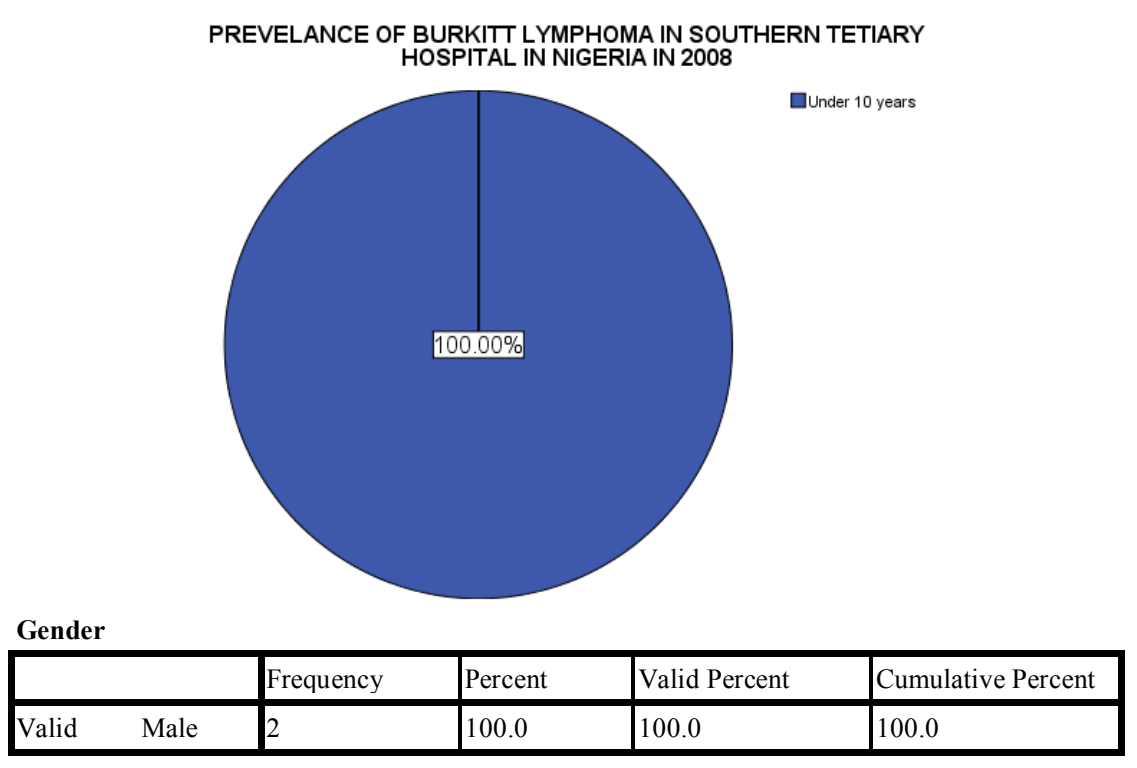

2009

\begin{tabular}{|c|c|c|c|c|c|}
\hline & & Frequency & Percent & Valid Percent & Cumulative Percent \\
\hline Valid & $10-20$ years & 1 & 100.0 & 100.0 & 100.0 \\
\hline
\end{tabular}

PREVELANCE OF BURKITT LYMPHOMA IN SOUTHERN TETIARY

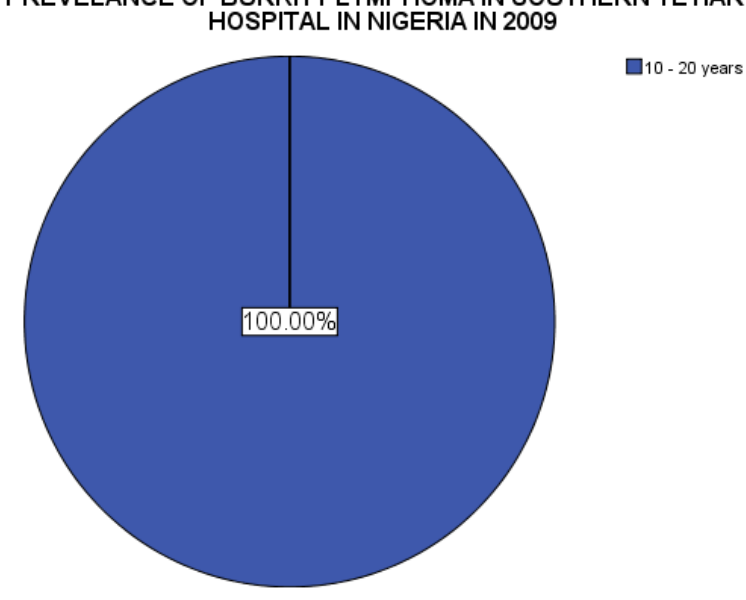

Gender

\begin{tabular}{|c|c|c|c|c|c|}
\hline & & Frequency & Percent & Valid Percent & Cumulative Percent \\
\hline & & $\begin{array}{l}1 \\
1\end{array}$ & $\begin{array}{l}100.0 \\
1000\end{array}$ & 100.0 & 100.0 \\
\hline
\end{tabular}

2010

Age in years
\begin{tabular}{|l|l|l|l|l|}
\hline & Frequency & Percent & Valid Percent & Cumulative Percent \\
\hline Valid $10-20$ years & 1 & 100.0 & 100.0 & 100.0 \\
Total & 1 & 100.0 & & \\
\hline
\end{tabular}




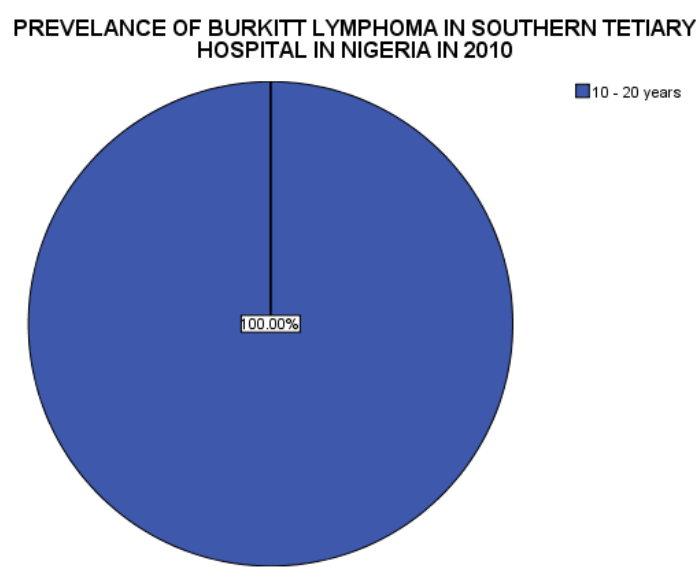

Gender

\begin{tabular}{|c|c|c|c|c|c|}
\hline & & Frequency & Percent & Valid Percent & Cumulative Percent \\
\hline $\begin{array}{l}\text { Valid } \\
\text { Total }\end{array}$ & Male & $\begin{array}{l}1 \\
1\end{array}$ & $\begin{array}{l}100.0 \\
100.0\end{array}$ & 100.0 & 100.0 \\
\hline
\end{tabular}

2012

Age in years
\begin{tabular}{|ll|l|l|l|l|}
\hline & Frequency & Percent & Valid Percent & Cumulative Percent \\
\hline Valid & Under 10 years & 1 & 100.0 & 100.0 & 100.0 \\
Total & 1 & 100.0 & & \\
\hline
\end{tabular}

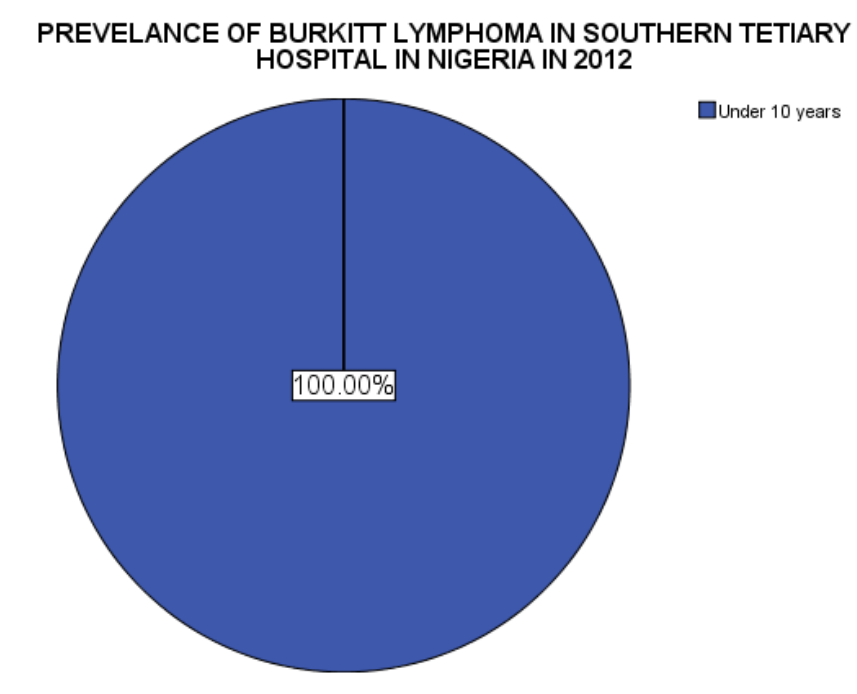

Gender

\begin{tabular}{|ll|l|l|l|l|}
\hline & & Frequency & Percent & Valid Percent & Cumulative Percent \\
\hline Valid & Female & 1 & 100.0 & 100.0 & 100.0 \\
Total & & 100.0 & & \\
\hline
\end{tabular}

A total of seven (7) were seen and diagnosed in the dept. of pathology showed preponderance to female in all the year of study. This occurring in 2008,2009 and 2010. That means that out of six years of the study retrospectively with exemption of 2011 where there is no cases seen male dominance was seen in three years of the study leaving barely two years for female gender making it a ratio of 3:1. It is imperative that in 2011 there was no case of BL seen; and in 2008 had two patients all male. 


\section{Discussion}

There is low level of occurrence of the lesion within the study period of Jan. 2007 - Dec.2012. The low figures seen may be attributed to a lot of factors ranging from ignorance to the disease which is peculiar with the disease. Most of these patients are noted to be of low socio-economic class as the disease is well seen in malnourished cases.Hence, the devout to either self-medication or herbal/alternative medicine treatment. In some other cases may be due to lack of early diagnosis or early death before presentation. This is because delay in presentation may lead to sudden death as the malignant cell of this lesion tends to be highly proliferative in nature.

This low incidencewithin the years of study have been seen in other studies in the Northern part of Nigeria where Ochicha et al did a similar study. Also in South west Nigeria, similar low incidence of BL was reported in Ibadan and Lagos. $15,16,17$

We noted a male preponderance in the study when compared with the female gender. Out of the seven years the male dominated in all the years of study except in 2012. The 2011 incidentally there was no lesion seen. In three years of the study 2008,2009 and 2010 the male gender was only seen. This is in support of previous study by Diebold Jetalet $\mathrm{al}^{18}$ where they noted that there is more male dominant and often in children. This is also seen in Cheng - Feng Bi et al ${ }^{19}$ study where the reported increase in male patients out of 43 cases evaluated in China.

BL despite been a highly aggressive lymphoma with doubling 25.6 hours is still curable. ${ }^{4}$ This is because intensive chemotherapeutic combination regimen could result to resolution of lesion to $90 \%$ with low stage disease and about $60-80 \%$ with patients in advanced stage. ${ }^{4}$ The toxicity resulting from therapy preclude its use in the elderly and in patients with endemic BL in developing nation hence leading to new strategies as Yustein et al reported. ${ }^{20}$

\section{Conclusion/Recommendation}

It is imperative in all cases of presentations of these patients once diagnosis is done for aggressive chemotherapy with central nervous system chemoprophylaxis to be instituted. In great importance is to initiate a program of free medication of all cancer patients cases with well notified centres in all the geo-political regions of our nation carried out by the media/government at all levels. We are of the opinion this will assist a lot of the patients who by their economic status could not afford therapy to approach such centres in time and avail themselves of such opportunity. These will go a long way in ameloriating and effective treatment in time and lower the burden to such low class citizens.

\section{Conflict Of Interest}

They authors declares no conflict of interests.

\section{Acknowledgement}

Thanks for the great contribution of the information technologist expert- Engr Anthony IfechiAnaedu for the pains taking to analyse this work.

Author:

Dr Martin Nnoli, Consultant Anatomic \& Forensic Pathologist. University of Calabar Teaching Hospital, Dept of Pathology \& Forensic Medicine, Calabar. Nigeria.

Co-authors:

Dr Collins Nwabuko O., Consultant Haematologist. Federal Medical centre Umuahia. Nigeria.

Dr ChinenyeNnoli, Senior Registrar.University ofUyo Teaching Hospital, Dept. of Paediatrics, Uyo. Nigeria.

\footnotetext{
[1] Synd/2511 at who named it?

[2] Burkitt D. A Sarcoma involving the jaws in African Children. The british Journal of Surgery 1971(46):218-23.doi:10.10.1002/bjs

[3] Dave S.S. et al. Molecular diagnosis of Burkitt Lymphoma. N. Engl. J. Med.2006;354.2431-2442.

[4] Siverdlow SH: WHO classification of tumorhaemopoietic and Lymphoid tissue.2008.Lyan:IARC.

[5] Hoffman Roland. Haematology: Basic Principle and Practice $5^{\text {th }}$ Edition.2009 Philadelphia, PA: Churchill Living Stone/Elservier. PP1304-1305.

[6] Liu D, Shimonor J, Primanneni S, Lai Y, Ahmed T et al. A 3 way chromosome translocation in two patients with BL/Leukaemia.2007. Mol. Cancer 6:35.doi 10.1186/1476-4598-6-35.

[7] Smardova J, Grochova D, Fabian P et al. An unusual P53 mutation detected in Burkitt Lymphoma: 30 bp duplication.2008 oncol.Rep.20(4):773-8 PMID18813817.

[8] Brady G.,MacArthur G.J, Farrel P.J. Epstein-Barr virus and Burkitt Lymphoma. Journal of Clinical Pathology 2007.60(12):13971402 .

[9] Bellan C.,Lazzi S, De Falco G et al. Burkitt Lymphoma: new Insights into Molecular pathogenesis. J clin. Pathol.56(3):8892.doi:10.1136/JCP.56.3.188.
}

References: 
[10] Chuang SS, Huang WT,Hsieh PP,Jung Yc,YCH, Du MQ et al. Sporadic Paediatric and adult BL share similar Phenotypic and genotypic features. Histopathology 2008;52:427-435.

[11] Lin H,Sun XF, Zhen ZJ: Clinical analysis of 69 cases of Burkitts Lymphoma. Ai Zheng 2008,27(4) 425-428. Chinese.

[12] Jaffe E: WHO classification of Neoplastic disease of the haemopietic and lymphoid tissue. 2001,Lyan:IARC.

[13] Rommel Lu. Primary Burkitt Lymphoma of the Chest wall. Hundawi Publishing corporation. Case reports in haematology vol 2012, article ID 746098,4 pages doi:10.1155/2012/746098.

[14] John T. Sandlund Jr. Burkitt Lymphoma: Staging and response evaluation. Br. J Haematol.2012;156(6) 761765.doi.10.1111/j.1365-2141.2012.09026.x.

[15] Akinde et al. Morphological Pattern of Childhood solid tumours in Luth. Nigeria Q. J. Hosp. Med. 2009;10:169-174.

[16] Ojesina AL, Akang EE et al. Decline in Burkitt Lymphoma relative to other Childhood Malignancies in Ibadan. Nigeria. Am Trop. Paediatr 2002;22:159-163.

[17] Tijani So, Elesha SO, Banjo AA. Morphological Pattern of Paediatric solid cancer in Lagos, Nigeria. West Afr J Med. 1995;14:174180.

[18] Diebold J et al. Burkitts Lymphoma. In Pathology and Genetics of Tumours of haemopoietic and lymphoid Tissues. Edited by Jaffe E, Harris N, Stein H. Washington, Dc: IARC Press;2001 :181-184.

[19] Cheng-Feng Bi, Yuan Tang, Wen-Yan Zhang et al. Sporadic Burkitt Lymphomas of Children and adolescents in Chinese: a clinicopathological Study of 43 cases. Diagnostic Pathology 2012,7.72http//www.diagnostic pathology.org/content/7/1/72.

[20] Yustein J.T, Dang C.V. Biology and Treatment of Burkitts Lymphoma. Curr.Opin. Haematol. 2007,14:375-381. 